\title{
The social component of the projection behavior of clausal complement contents
}

\author{
Taylor Mahler*
}

\begin{abstract}
Some accounts of presupposition projection predict that content's consistency with the Common Ground influences whether it projects (e.g., Heim 1983; Gazdar 1979a,b). I conducted an experiment to test whether Common Ground information about the speaker's social identity influences projection of clausal complement contents (CCs). Participants rated the projection of CCs conveying stereotypical liberal or conservative political positions when the speaker was either Democrat- or Republican-affiliated. As expected, CCs were more projective when they conveyed political positions consistent with the speaker's political affiliation: liberal CCs were more projective with Democrat compared to Republican speakers, and conservative CCs were more projective with Republican compared to Democrat speakers. In addition, CCs associated with factive predicates (e.g., know) were more projective than those associated with non-factive predicates (e.g., believe). These findings suggest that social meaning influences projective meaning and that social meaning is constrained by semantic meaning, in line with previous research on the relation between other levels of linguistic structure/perception and social information.
\end{abstract}

Keywords. presupposition; projection; factivity; social meaning

1. Introduction. When speakers presuppose content, they often convey their commitment to its truth even when the content is not entailed. Consider the content of the complement (henceforth CC) of know in (1), i.e., Obama improved the American economy. In each sentence, the complement of know is embedded within the syntactic scope of an entailment-cancelling operator: negation in (1-a), a question in (1-b), an epistemic modal in (1-c), and an antecedent of a conditional in (1-d). Nevertheless, the sentences in (1) permit readings on which the speaker is taken to be committed to truth of the CC of know. Content that displays such behavior is said to project (e.g., Kiparsky \& Kiparsky 1970; Karttunen 1971): despite being expressed by a constituent that is embedded within the scope of an entailment-cancelling operator, the speaker can be taken to be committed to the content's truth.

(1) a. Cindy doesn't know that Obama improved the American economy.

b. Does Cindy know that Obama improved the American economy.

c. Cindy might know that Obama improved the American economy.

d. If Cindy knows that Obama improved the American economy, she'll vote for him.

The ability to project has historically been regarded as the defining property of presupposition. Hence, the classical answer to the question of why content projects is that it is presupposed (e.g., Heim 1983, 1992; van der Sandt 1992).

Clause-embedding predicates are often assumed to divide into two classes depending on whether they lexically encode the presupposition of their complements: factive predicates like know encode this presupposition, whereas non-factive predicates like think and believe do not

* Thanks to Kathryn Campbell-Kibler, Marie Catherine de Marneffe, and Ashwini Deo for guidance on this project, as well as the SoMean and Pragmatics discussion groups at Ohio State for helpful feedback. Author: Taylor Mahler, The Ohio State University (mahler.38@ osu.edu) 
(Kiparsky \& Kiparsky 1970). On such lexically-based accounts of presupposition, presuppositions project unless they conflict with other information in the Common Ground (Heim 1983; Gazdar 1979a,b; van der Sandt 1992). Thus, in the absence of information that conflicts with with the $\mathrm{CC}$ of know in (1), these accounts predict that the CC projects.

Other approaches derive (at least some cases of) presupposition projection from general pragmatic principles (e.g., Stalnaker 1974; Boër \& Lycan 1976; Karttunen \& Peters 1979; Simons 2001, 2005; Abrusán 2011). A prominent and well-developed approach within this camp has proposed that information-structural properties of utterances predict projection behavior (e.g., Abbott 2000; Simons 2001, 2007; Simons et al. 2010, 2017; Beaver et al. 2017; Tonhauser et al. 2018). Proponents of this approach hypothesize that whether content projects depends on whether it is at-issue in the discourse. Content that addresses the Question Under Discussion (QUD; Roberts 1996/2012) is at-issue and predicted to be non-projective. Content that does not address the QUD is not-at-issue and predicted to project. For example, when (1-a) is uttered in a context in which the QUD is Did Obama improve the American economy?, the CC of know is predicted not to project since it addresses the QUD and is hence at-issue. When the same sentence is uttered in a context in which the QUD is What cognitive relation does Ben have to the proposition that Obama improved the American economy?, the CC of know is predicted to project since it does not address the QUD and is hence not-at-issue.

These approaches highlight two different properties of content that have been implicated in projection: consistency with the Common Ground and at-issueness. As Beaver et al. (2017) point out, these properties are related: content that is entailed by, and hence consistent with, the Common Ground is not-at-issue and predicted to project.

However, content that is not entailed by the Common Ground may be either at-issue or not-at-issue, depending on the QUD. It is possible that the projection of content not entailed by the Common Ground is influenced by both Common Ground consistency and the QUD/atissueness, or that these properties influence one another. Here, I focus on the former of these two properties in isolation, leaving for future research the task of determining their relation to each other and to the projection of content that is not entailed by the Common Ground.

In investigating the property of Common Ground consistency, the current study builds on research from Tonhauser \& Degen (2019), who manipulated the CC's consistency with the Common Ground by providing information relevant to the truth of the CC. Tonhauser \& Degen (2019) found that the CC is more projective when it is highly probable by virtue of the Common Ground information compared to when it is less probable, suggesting that inconsistency with the Common Ground interferes with projection. The primary goal of the current study is to investigate whether consistency with a particular type of Common Ground information - social information about the speaker - influences CC projection. A second goal is to investigate whether these (in)consistencies are dependent on the factivity of the clauseembedding predicate. These two aims are articulated in the research questions in (2):

(2) Research Questions:

a. For clausal complement contents (CCs), is projection sensitive to consistency between the contents and Common Ground information about the speaker's social identity?

b. Is the effect of consistency dependent on the factivity of the clause-embedding predicate? 
I explore these research questions on the basis of an experiment in which participants were presented with target sentences like (1-a). Consistency between the $\mathrm{CC}$ and Common Ground information about the speaker's social identity was operationalized by manipulating two variables, as demonstrated in (3). The lexical content instantiating the clausal complement was manipulated such that it conveyed either a liberal political position (Obama improved the American economy) or a conservative political position (Obama damaged the American economy). The speaker's political affiliation was manipulated by presenting each sentence as the utterance of either a Republican or Democrat-affiliated speaker.

Cindy doesn't $\{$ know/believe $\}$ that Obama $\{$ improved, damaged $\}$ the American economy.

If consistency with Common Ground social information influences projection, CCs that are consistent with liberal ideologies will project more with Democrat speakers and CCs that are consistent with conservative ideologies will project more with Republican speakers, compared to when the speaker is affiliated with the opposing party.

In order to address the second research question, the factivity of the clause-embedding predicates was also manipulated. Each lexical content was presented as the complement of one factive predicate like know and one non-factive predicate like believe. If projection is a consequence of lexically-encoded presupposition, as assumed by lexically-based accounts of projection, then factivity should influence the projection of CCs. Specifically, the CCs of factive predicates should be more projective than those of non-factive predicates, and may also constrain the effect of Common Ground consistency on projection.

2. Accounting for projection behavior: existing accounts. Lexically-based analyses of projection start with the assumption that projection is a consequence of lexically-encoded presupposition (e.g., Karttunen 1974; Heim 1983, 1992; Gazdar 1979a,b; van der Sandt 1992; Schlenker 2008). Presuppositions are then subject to a requirement with respect to the Common Ground: the presupposition must be entailed by (Heim 1983) or satisfied in the Common Ground (van der Sandt 1992). In the simplest case, the presupposition is already part of the Common Ground, i.e, the speaker and addressee already have mutual knowledge of the presupposed information. If the presupposition is not already in the Common Ground but the speaker's utterance is nevertheless felicitous, the addressee simply adds the presupposed information to the Common Ground. This process is called global accommodation (e.g., Heim 1983). In both cases, the speaker is interpreted as having expressed commitment to the truth of the presupposition by taking it to be in the Common Ground, i.e., the presupposition is felt to project to the Common Ground of the interlocutors.

Among the presupposition "triggers" that have been claimed to lexically-encode presuppositions are a subset of clause-embedding predicates called factives (Kiparsky \& Kiparsky 1970). Kiparsky \& Kiparsky (1970) distinguished factive predicates like regret, know and realize from non-factive predicates on the basis of both syntactic and semantic properties, but semantically they were differentiated on the basis of the presupposition of the CC. Whereas factive predicates are assumed to lexically encode their CCs as presuppositions, non-factive predicates are not. Projection then follows from presupposition: the CCs of factives are predicted to project, in contrast to those of non-factives.

As many observations in the literature attest, the CCs of factive predicates do not always project. Just one year after Kiparsky \& Kiparsky (1970) introduced the factive/non-factive di- 
vision, Karttunen (1971) pointed out that some factives (e.g., regret) seem to allow only projective interpretations, whereas others like discover admit both projective and non-projective interpretations. To capture this difference, he coined the term semi-factive for predicates like discover that can exhibit variable projection behavior, distinguishing them from predicates like regret that do not.

Factive presuppositions can also fail to project when they conflict with other contextual information. Simons (2001), following comments from Geurts (1999) and Chierchia \& McConnellGinet (1990), pointed out that factive presuppositions do not project in "explicit ignorance contexts". She offers the example in (4), in which the CC of discover is embedded under the entailment-cancelling epistemic modal adverb perhaps.

(4) [Context: At a restaurant, the interlocutors observe a couple arguing at another table.] Speaker: Perhaps she just discovered that he's having an affair.

Since neither interlocutor is acquainted with the couple, the addressee believes that the speaker has no knowledge of the man's behaviors. Hence, the addressee does not take the speaker to be committed to the $\mathrm{CC}$ of discover. Instead, the addressee interprets the speaker as suggesting that it is possible that he had an affair, and that if he has had one her discovery of it may be the reason for the argument.

The mechanism that is standardly invoked to account for the observation that presuppositions do not always project is local accommodation (Heim 1983). Central to this process are the notions of global and local contexts (Karttunen 1974; Stalnaker 1974; Heim 1983). An entire sentence is evaluated with respect to the information in the global context, i.e., the Common Ground. But constituent sentences may instead be evaluated with respect to local contexts, prior to updating the global context. In (4), the CC of discover could be locally accommodated by being evaluated within the scope of the modal adverb. The speaker is then interpreted as believing that the affair is a possibility, without being certain that it happened.

Others have proposed that presuppositions are simply cancelled when they conflict with Common Ground information (e.g., Gazdar 1979a,b; van der Sandt 1988). Gazdar (1979a,b) outlines an account in which presuppositions project by default, but are cancelled if they conflict with the speaker's prior set of commitments. Presuppositions only project if they do not conflict with prior speaker commitments contributed by implicatures, entailments, or other extra-linguistic information. When such a conflict emerges, the presupposition does not project to the Common Ground.

The approaches described thus far in this section assume that projection is a consequence of presupposition. But other authors have pointed out that content need not be presupposed in order to project (e.g., Chierchia \& McConnell-Ginet 1990; Potts 2005). For example, several authors have noted based on examples like (5) from Chierchia \& McConnell-Ginet (1990) that appositive expressions contribute content that is not presupposed, and nevertheless projects (Chierchia \& McConnell-Ginet 1990; Potts 2005): the speaker has not presupposed that Jill lost something on her flight, but is nevertheless taken to be committed to this content.

(5) Jill, who lost something on the flight from Ithaca to New York, doesn't like to travel by train.

Intonation also seems to influence whether content projects. Beaver (2010), for example, pointed out the CC of discover in (6) seems not to project when a constituent within the complement 
(e.g., plagiarized in (6)) is narrowly focused; when narrow focus is outside of the complement (e.g., when discovers is focused), the sentence receives a projective reading with respect to the CC. Later experimental work confirmed the intuition that prosody influences the projection of factive CCs (Cummins \& Rohde 2015; Tonhauser 2016; Djärv \& Bacovcin 2017).

(6) a. If the TA discovers that your work is PLAGIARIZED, I will be forced to notify the dean.

b. If the TA DISCOVERS that your work is plagiarized, I will be forced to notify the dean.

In light of observations like these, recent work has attempted to provide a unified analysis of both presuppositional and non-presuppositional projective meanings in terms of information structure (e.g., Simons et al. 2010; Beaver et al. 2017; Simons et al. 2017). At the core of this analysis is Roberts' (1996/2012) Question Under Discussion (QUD), i.e., the semantic question corresponding to the current topic of discourse. In (7), for example, Rachel's utterance could be intended to address either QUD1 or QUD2.

QUD1: What does the pizza have on it?

QUD2: What is Ben's relation to the proposition the pizza has olives on it?

Rachel: Ben doesn't know that the pizza has olives on it.

Whereas the CC addresses QUD1, it does not address QUD2. In their Projection Principle, Beaver et al. (2017) hypothesized that this property of the CC predicts whether it projects: content that addresses the QUD, at-issue content, is hypothesized not to project; content that does not address the QUD, not-at-issue content, is hypothesized to project (see also Simons et al. 2010, 2017).

Like the lexically-based accounts, the Projection Principle predicts that content that is entailed by the Common Ground projects. Beaver et al. (2017) explain that this prediction follows from the assumption that the Common Ground and the QUD ought to be compatible with one another. That is, the QUD should not be about the truth of the content that is entailed by the Common Ground; hence content entailed by the Common Ground is not-at-issue, and therefore projects.

But the Projection Principle and lexically-based accounts make different predictions about the projection of content that is not entailed by the Common Ground. On the informationstructural accounts outlined above, the QUD determines whether the content is (not-)at-issue and this property predicts whether it will project. On lexically-based accounts, however, only content associated with a presupposition trigger has the potential to project, and it is predicted to do so unless it conflicts with other information in the Common Ground.

The experiment reported in this paper is designed to investigate the projection of content that is not entailed by the Common Ground, and whether its ability to project is sensitive to a particular property: consistency with the Common Ground. Though the influence of this property on projection is associated with lexically-based accounts of projection, it is in principle possible that both Common Ground consistency and information-structural properties such as at-issueness influence projection of content (i.e., content not entailed by the Common Ground). This study is not intended to explore the interaction of these two properties, and leaves this task to future research. However, I do consider the possibility that content may project even when it is not associated with a canonical presupposition trigger, a possibility which is con- 
sistent with information-structural but not lexically-based projection accounts. In particular, I investigate the extent to which consistency with the Common Ground influences the projection of CCs associated with factive predicates - which are canonical presupposition triggers - as well as non-factive predicates, which are not assumed by lexically-based accounts to encode their complements as presuppositions.

3. Social and linguistic meaning. As discussed in section 2, consistency with the Common Ground has been implicated as property of content that influences projection. Such Common Ground information can come from a variety of sources - prior utterances, entailments or implicatures of the uttered sentence, or implicit reasoning about the extralinguistic context (e.g., Heim 1983; Gazdar 1979a,b). In this paper, I investigate an aspect of the extralinguistic context that hasn't been explored in the projection literature: the speaker's social identity.

The hypothesis that projection is sensitive to social information is motivated by robust evidence from the sociolinguistic literature that linguistic structure and social information are intimately connected in the minds of speakers/hearers. For example, listeners have been shown to use information about speaker region (e.g., Niedzielski 1999; Hay \& Drager 2010), age (e.g., Drager 2011) and gender (e.g., Strand 1999) in speech perception. D'Onofrio (2018) showed that the speaker's construction of a unique social personae (e.g., a valley girl or business professional) influences the perception of the speaker's vowels.

Social information has also been found to influence lexical access. A common experimental paradigm in this literature involves manipulating a speaker characteristic like age, as well as the content of the sentence, such that the content is either congruent with the speaker characteristic (e.g., an adult talking about drinking wine) or incongruent (e.g., a child talking about drinking wine). In brain-imaging research, incongruent stimuli are associated with brain responses that are similar to the responses associated with other types of linguistic anomalies (e.g., semantically anomalous words), leading researchers to conclude that the same sorts of neural mechanisms underlie the processing of linguistic and social information (e.g., Van Berkum et al. 2008; Tesink et al. 2009). In lexical access research that uses reaction time or offline dependent measures, the processing of the word that creates the anomaly has been found to be impeded (Kim 2016; Walker \& Hay 2011; Choe et al. 2019). Casasanto (2008) implemented a variation of the incongruity paradigm in which listeners were presented with pairs of spoken sentences that were temporarily ambiguous between two interpretations. On one interpretation the word of interest exhibited a feature of African American Vernacular English, a final / $t$ / or /d/ that had been deleted (e.g., mast pronounced as [mæs]). In the other interpretation, there was no underlying final stop (e.g., mass pronounced as [mæs]). Casasanto (2008) found that participants responded faster to the sentence continuation that was compatible with the deleted final stop interpretation when the speaker was black, and faster to the sentence continuation that was compatible with there being no underlying final stop when the speaker was white.

Syntactic processing, too, has been shown to be sensitive to social information. In a brain imaging study of native listeners, Hanulíková et al. (2012) found that gender-agreement violations in Dutch elicited a neural response associated with encountering ungrammaticality when the speaker was native Dutch speaker, but not when the speaker was non-native. Similarly, Seifeldin et al. (2015) found that native Standard American English (SAE) listeners' neural responses to copula deletion was modulated by the dialect of the speaker: the characteristic response for ungrammaticality appeared for native SAE speakers, but not for native speakers of 
other English dialects.

Though research exploring the interface between social and semantic-pragmatic meaning is sparse, a recent strand of scholarship has attempted to unify these two domains. Andrea Beltrama's work focuses on the social and semantic-pragmatic meaning of linguistic expressions conveying intensification and precision. With respect to intensifiers, he showed that totally has greater potential to index social meaning when it targets a pragmatically-provided scale anchored to the speaker's attitude (e.g., You should totally click on that link!) vs. a lexical scale provided by the subsequent predicate (e.g., The bus is totally full.) (Beltrama \& Staum Casasanto 2017; Beltrama 2018a). In other work, Beltrama (2018b) found that speakers who use more precise expressions (e.g., Ben called at 9.03) are perceived as more intelligent, educated and articulate but also more annoying, obsessive, pedantic and uptight than speaker who use less precise expressions (e.g., Ben called at 9). He interprets these finding as evidence that semanticpragmatic properties of expressions conveying linguistic intensification and precision constrain their social meaning.

In addition to linguistic precision and intensification, determiners have also been the subject of research at the interface of semantic-pragmatic and social meaning. Acton \& Potts (2014) argued that the semantics of demonstrative determiners facilitates their ability to convey social meaning; in particular speakers can use demonstratives to convey shared perspective with their interlocutors. Acton (2019) further showed that the semantics of plural determiner phrases (e.g., The Americans) allow speakers to express social distance from the addressee, in contrast to bare plural phrases (e.g., Americans)

To summarize, there is robust evidence that social information influences linguistic processing and perception at multiple levels of linguistic structure. However, within semantics and pragmatics, research has focused on whether this relationship goes in the other direction, i.e., whether linguistic (semantic-pragmatic meaning) influences social perception. Here, I bring these two lines of inquiry together by investigating whether semantic-pragmatic meaning - particularly projective meaning - is influenced by social information. Further, in light of the prior research showing that semantic meaning constrains social perception, I explore the extent to which the effect of social information on projection is mediated by lexical semantics, specifically the factivity of clause-embedding predicates.

4. Experiment. The projective contents explored in the experiment were the contents expressed by the complements of clause-embedding predicates. (In)consistency between the CC and the Common Ground was operationalized by manipulating the political orientation of the lexical content instantiating the clausal complement (conservative vs. liberal) and the political affiliation of the speaker (Republican vs. Democrat). Factivity of the clause-embedding predicate was manipulated by presenting each lexical content as the complement of a factive predicate and a non-factive predicate.

Participants provided projection ratings for the same stimuli in two separate experimental blocks, one in which the speaker was Republican-affiliated and one in which the speaker was Democrat-affiliated. Projectivity was measured using the 'certainty' diagnostic (e.g., Tonhauser 2016; Stevens et al. 2017; Tonhauser et al. 2018). This diagnostic assesses speaker commitment by asking participants to indicate the extent to which the speaker is certain about the content of interest. 
4.1. PARTICIPANTS. 200 participants were recruited on Amazon's Mechanical Turk platform and paid $\$ 1.25$ for participating in the experiment. ${ }^{1}$ Participants had US IP addresses and at least $97 \%$ of previous HITs approved. Data from non-native American English speakers (N=5) and participants who responded incorrectly to control items $(\mathrm{N}=46)$ was removed, leaving data from 149 participants.

4.2. MATERials. Each target sentence featured a third-person matrix subject, a clause-embedding predicate, and a clausal complement. The predicate and complement were embedded under negation, as in (8).

(8) Cindy doesn't know that

a. Obama damaged the American economy.

b. Obama improved the American economy.

conservative $C C$

c. club membership numbers have increased.

liberal $C C$

neutral CC

Seven clause-embedding predicates were used to construct the target sentences: the factive predicates know, realize and see and the non-factive predicates believe, think and feel.

The clausal complements were instantiated by 42 lexical contents. 28 of these were "political" lexical contents that conveyed a position regarding 1 of 14 political topics (e.g., Obama, marriage equality etc.). For each topic, one lexical content conveyed a stereotypical liberal positions and one conveyed a stereotypical conservative position. These lexical contents were normed in a separate experiment to ensure that they were associated with the intended political orientation. $^{2}$

The other 14 lexical contents were each associated with 1 "neutral" topic. These topics were unrelated to politics (e.g., club membership numbers). The neutral topics were included in order to confirm that the CCs in sentences uttered by Democrats were not perceived as more projective than Republicans, or vice versa. Participants might have preexisting beliefs that affiliates of one political party are more certain about their claims than the affiliates of the other party. If this were the case, observed differences in projectivity could be driven by this preexisting belief, rather than interactions between social information and the CC. If participants don't hold this preexisting belief, then the projection of neutral CCs should be equivalent regardless of whether the speaker is Democrat- or Republican-affiliated.

Each lexical content was combined with 2 predicates ( 1 factive and 1 non-factive in most cases). For political topics, the conservative and liberal lexical contents were each combined with the same predicate. In total, there were 84 predicate/lexical content pairs, which were used to construct 84 target sentences.

Target stimuli were constructed by presenting each target sentence once as the utterance of a speaker attending a meeting College Democrats, and once as the utterance of a speaker attending a meeting of College Republicans, as in (9).

\section{(9) a. Republican speaker, conservative CC}

Cindy, at the College Republicans Club meeting:

Ben doesn't \{know/believe $\}$ that Obama damaged the American economy.

\section{b. Democrat speaker, conservative $\mathbf{C C}$}

\footnotetext{
1 The experiment was conducted with IRB approval.

${ }^{2}$ See http://github.com/taylor5768/QP2-Social-meaning-and-projection for the all experimental materials, including the materials used in the norming experiment
} 
Cindy, at the College Democrats Club meeting:

Ben doesn't $\{$ know/believe $\}$ that Obama damaged the American economy.

c. Republican speaker, liberal CC

Cindy, College Republicans Club meeting:

Ben doesn't \{know/believe $\}$ that Obama improved the American economy.

d. Democrat speaker, liberal CC

Cindy, at the College Democrats Club meeting:

Ben doesn't $\{$ know/believe $\}$ that Obama improved the American economy.

The 84 target sentences were distributed across 4 presentation lists. On each list, there were 14 target sentences with complements instantiated by politically-oriented lexical contents ("political target sentences") and 7 target sentences with complements instantiated by neutral lexical contents ("neutral target sentences"). Each target sentence was presented once as the utterance of a Republican-affiliated speaker and once as the utterance of a Democrat-affiliated speaker. Each list included exactly three target sentences per predicate and no more than one target sentence per topic. For half of the 14 political target sentences on each list, the complements were instantiated by conservative lexical contents; the complements of the other political target sentences were instantiated by liberal lexical contents.

In order to assess whether participants were paying attention, two control lexical contents were also constructed. These lexical contents were apolitical, and expressed by main clauses that were not embedded under entailment-cancelling operators, as in (10). They were therefore expected to be interpreted as commitments of the speaker and receive high certainty ratings regardless of the type of meeting attended by the speaker. Each control lexical content appeared on each list twice, once as the utterance of a Democrat-affiliated speaker and once as the utterance of a Republican-affiliated speaker. In total, there were 46 stimuli on each list. A short demographic questionnaire was also included in which participants provided standard demographic information (age, native language. etc.) as well as information about their own political affiliation.

(10) a. Carly, at the College Democrats Club meeting:

Alan brought the cookies for dessert.

b. Larry, at the College Democrats Club meeting:

Olivia missed the meeting because she's sick.

4.3. Procedure. Each participant was randomly assigned to 1 of the 4 presentation lists. Participants completed the experiment in two separate experimental blocks. At the beginning of each block, participants were told to imagine a meeting at a university campus. In one block, they were told to imagine a meeting of the College Republicans Club. In the other block, they were told to imagine a meeting of the College Democrats club. In the Republican block, participants saw the 23 stimuli on their list with Republican speakers. In the Democrat block, they saw the 23 stimuli on their list with Democrat speakers. Block order and within-block trial order were randomized.

On each target stimulus trial, participants read the the speaker's utterance followed by a response question about the speaker's certainty with respect to the $\mathrm{CC}$, as shown in Figure 1. Participants gave their responses by adjusting a slider labeled on the left with "No, not certain" (corresponding to a rating of 0 ) and on the right with "Yes, certain" (corresponding to a rating 
of 1). The higher the response, the more projective the CC was taken to be.

The response question for the control stimuli was about the main clause content (Is Carly certain that Alan brought the cookies for dessert? and Is Larry certain that Olivia missed the meeting because she's sick?). ${ }^{3}$ After completing both blocks of the experiment, participants completed a demographic questionnaire.

Cindy, at the College Republicans Club meeting:

Ben doesn't believe that Obama improved the American economy.

Is Cindy certain that Obama improved the American economy?

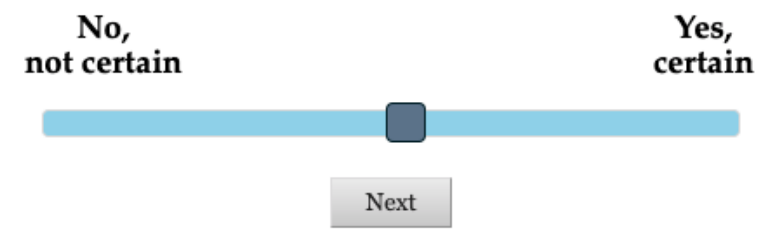

Figure 1. Sample trial in the main experiment

4.4. RESUlTS. The experiment was designed to address the research questions in (2). In this section, I report the experimental results that bear on these questions. First, I confirm that the projectivity of the stimuli with neutral CCs was not sensitive to the political affiliation of the speaker. Second, I report the results for the stimuli with political CCs. These results suggest that both the factivity of the clause-embedding predicate and the speaker's political affiliation independently influenced $\mathrm{CC}$ projection.

The responses to stimuli with neutral CCs were analyzed with a linear mixed-effects model. The full model included fixed effects for predicate factivity (factive vs. non-factive), the political affiliation of the speaker (Republican vs. Democrat), and their interaction. The maximal random effects structure for which the model converged included random intercepts for item and participant. $p$-values for fixed effects were obtained using log-likelihood comparisons between the full model against a model without the effect in question.

The fixed effect of predicate factivity was significant, such that the CCs of factive predicates received higher ratings than those of non-factive predicates $(\beta=0.28, S E=0.03, t=$ $\left.10.98, \chi^{2}(1)=50.05, p<0.0001\right)$. The fixed effect of speaker political affiliation was not significant $\left(\beta=0.003, S E=0.01, t=0.20, \chi^{2}(1)=0.56, p=0.46\right)$, nor was the interaction fixed effect $\left(\beta=.01, S E=0.02, t=0.37, \chi^{2}(1)=0.56, p=0.71\right)$. This suggests that participants did not have preexisting beliefs that speakers affiliated with a particular party were more certain about their claims.

The responses to stimuli with political CCs were analyzed with a linear mixed-effects model. The full model included fixed effects for predicate factivity (factive vs. non-factive), the political affiliation of the speaker (Republican vs. Democrat), and the political orientation of the CC (conservative vs. liberal) and all 3- and 2-way interactions. The maximal random effects structure for which the model converged included random intercepts for item and participant, as well as by-item and by-participant slopes for speaker political affiliation and the political orientation of the CC. $p$-values for fixed-effects were obtained using log-likelihood comparisons between the full model against a model without the effect in question.

\footnotetext{
${ }^{3}$ Responses less than .6 on the rating scale were considered incorrect.
} 
Figure 2 visualizes mean ratings as a function of speaker political affiliation and political orientation of the $\mathrm{CC}$, grouped according to the factivity of the predicate. As suggested by the figure, there was a significant interaction between the political orientation of the $\mathrm{CC}$ and speaker's affiliation $\left(\beta=0.19, S E=0.15, t=13.12, \chi^{2}(1)=168.14, p<0.0001\right)$. For clausal complements instantiated by liberal lexical contents, ratings were higher when the speaker was Democrat-affiliated (mean $=.66$ ) than Republican-affiliated (mean $=.56$ ). For clausal complements instantiated by conservative lexical contents, ratings were higher when the speaker was Republican-affiliated (mean $=.64$ ) than Democrat-affiliated (mean =.55). The three-way interaction between political orientation, speaker affiliation, and predicate factivity did not reach significance $\left(\beta=0.01, S E=0.03, t=0.39, \chi^{2}(1)=0.15, p=0.70\right.$ ).

Figure 3 visualizes mean ratings by predicate and factivity, suggesting that ratings were higher when the predicate was factive (mean $=0.69$ ) compared to when it was non-factive (mean $=0.48$ ). This qualitative observation was confirmed statistically: there was a significant main effect of predicate factivity, such that the CCs of factive predicates received higher ratings than those of non-factive predicates $\left(\beta=0.22, S E=0.02, t=9.99, \chi^{2}(1)=40.66, p<\right.$ 0.0001).

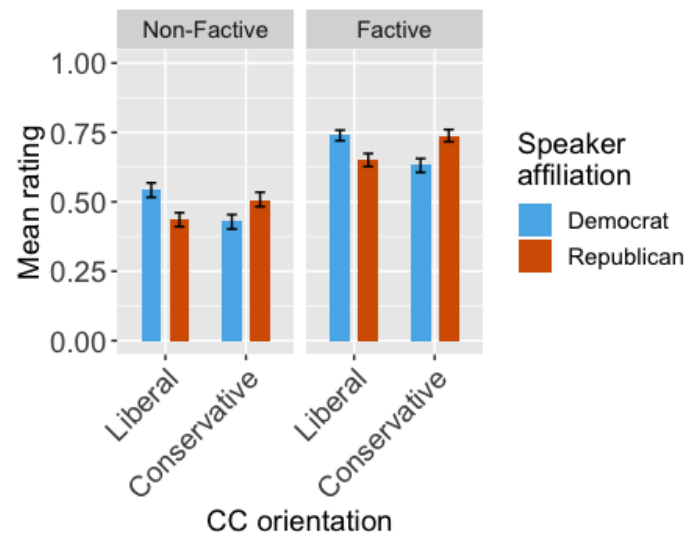

Figure 2. Mean projection ratings by complement political orientation and speaker affiliation (with $95 \%$ confidence intervals)

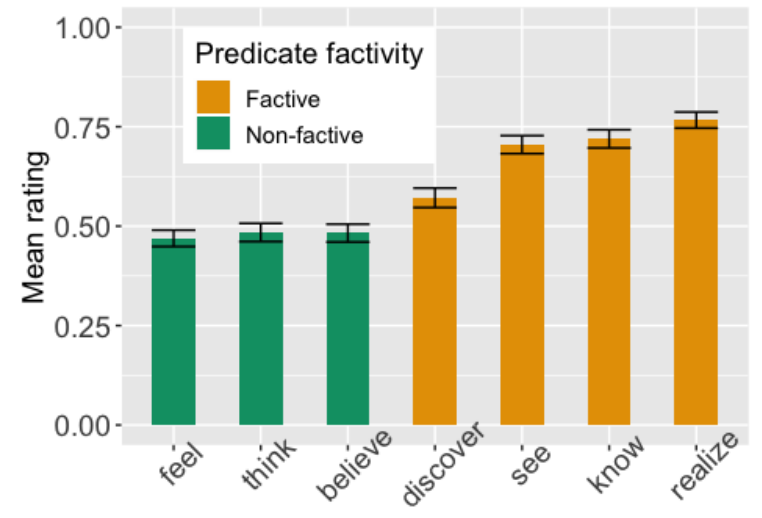

predicate predicate for political items (with $95 \%$ confidence intervals)

4.5. Discussion. This experiment was designed to investigate the effects of two properties on projection: (1) (in)consistency between projective content and Common Ground information about the speaker's social identity, and (2) the factivity of the clause embedding predicate.

As expected, CC projection was sensitive to consistency between the lexical contents instantiating the complements and Common Ground information about the speaker's social identity. Consistency between the lexical content instantiating the clausal complement and the speaker's social identity led to higher projection ratings than inconsistency: when the complement was instantiated by a liberal lexical content, projection ratings were higher when the speaker was Democrat; when the complement was instantiated by a conservative lexical content, projection ratings were higher when the speaker was Republican. This finding is compatible with accounts of projection that attribute non-projective interpretations of factive presuppositions to local accommodation (e.g., Heim 1983) or cancellation (e.g., Gazdar 1979a,b; van der Sandt 1992). 
This finding also demonstrates that the social identity of the speaker is an important source of information about whether projective content is consistent with the Common Ground. Listeners draw inferences about speaker beliefs based on information about the speaker's social identity and use these inferences to reason about whether content is consistent with the Common Ground; in short, social information influences projective meaning.

The factivity of the clause-embedding predicate was also found to influence projection, independently of whether the lexical content instantiating the complement was consistent with the Common Ground information about the speaker's social identity. CCs were more projective when the predicate was factive compared to when it was non-factive, regardless of the speaker's political affiliation. This finding is compatible with the assumption that factive predicates lexically-encode their complements as presuppositions, whereas non-factive predicates do not.

In sum, the findings of this experiment suggest that factivity and consistency with Common Ground information about the speaker's social identity independently influence projection. Common Ground (in)consistency can influence $\mathrm{CC}$ projection regardless of predicate factivity. However, such (in)consistency is not sufficient to override the effect of factivity, suggesting that the semantics of the clause-embedding predicates constrain the effects of social information.

5. Conclusion. Consistency between projective content and the Common Ground has previously been implicated as a property that influences projection (e.g., Heim 1983; van der Sandt 1992; Gazdar 1979a,b). In this paper, I investigated whether projection is sensitive to Common Ground information about the speaker's social identity. The findings suggest that such information bears on how listeners reason about the consistency of the Common Ground with projective content: contents were more projective when they conveyed political positions consistent with the speaker's social identity than when they were not. Given that social information has been found to influence comprehension/perception in many other linguistic domains, this finding is expected and confirms that semantic-pragmatic meaning is also subject to influence from such information. In addition, the finding that social information about the speaker did not override the effects of the predicate's factivity suggests that semantic meaning limits the extent to which social information influences projective meaning, in line with prior research showing that semantic-pragmatic meaning constrains social perception.

Together with recent work, the findings of this study highlight that social and semanticpragmatic meaning are more closely connected than often assumed, thereby motivating future research at the interface of these two types of meaning. With respect to projective meaning, an interesting question is whether less explicit cues to speaker social identity also influence projection, for example, the use of sociolinguistic variants (e.g., -ing vs. -in). It remains for future research to determine whether such cues also play a role, and how their effects ought to be incorporated into a theory of projection.

\section{References}

Abbott, Barbara. 2000. Presuppositions as nonassertions. Journal of Pragmatics 32(10). 14191437.

Abrusán, Márta. 2011. Predicting the presuppositions of soft triggers. Linguistics and Philosophy 34(6). 491-535. https://doi.org/10.1007/s10988-012-9108-y. 
Acton, Eric K. 2019. Pragmatics and the social life of the English definite article. Language 95(1). 37-65. https://doi.org/10.1353/lan.2019.0010.

Acton, Eric K. \& Christopher Potts. 2014. That straight talk: Sarah Palin and the sociolinguistics of demonstratives. Journal of Sociolinguistics 18(1). 3-31. https://doi.org/10.1111/josl.12062.

Beaver, David. 2010. Have you noticed that your belly button lint colour is related to the colour of your clothing. In Rainer Bäuerle, Uwe Reyle \& Ede Zimmerman (eds.), Presuppositions and discourse: Essays offered to Hans Kamp. 65-99. Bingley, UK: Emerald Group.

Beaver, David, Craige Roberts, Mandy Simons \& Judith Tonhauser. 2017. Questions under discussion: Where information structure meets projective content. Annual Review of Linguistics 3. 265-284. https://doi.org/10.1146/annurev-linguistics-011516-033952.

Beltrama, Andrea. 2018a. Intensification, gradability and social perception: The case of totally. In Elena Castroviejo, Louis McNally \& Galit Weidman Sassoon (eds.), The Semantics of gradability, vagueness, and scale structure. 169-197. Berlin: Springer.

Beltrama, Andrea. 2018b. Precision and speaker qualities. The social meaning of pragmatic detail. Linguistics Vanguard 4(1). https://doi.org/10.1515/lingvan-2018-0003.

Beltrama, Andrea \& Laura Staum Casasanto. 2017. Totally tall sounds totally younger: Intensification at the socio-semantics interface. Journal of Sociolinguistics 21(2). 154-182. https://doi.org/10.1111/josl.12230.

Boër, Steven E \& William G Lycan. 1976. The myth of semantic presupposition. In Arnold Zwicky (ed.), Papers in nonphonology (Working Papers in Linguistics 21). 1-90. Columbus, $\mathrm{OH}$ : The Ohio State University.

Casasanto, Laura Staum. 2008. Does social information influence sentence processing? Proceedings of the Annual Meeting of the Cognitive Science Society 30. 799-804. https://escholarship.org/uc/item/8dc2t2gf.

Chierchia, Gennaro \& Sally McConnell-Ginet. 1990. An Introduction to semantics. Cambridge, MA: MIT Press.

Choe, June, Shayne Sloggett, Yoshida Masaya \& Annette D’onofrio. 2019. Personae in syntactic processing: socially-specified agents bias expectations of verb transitivity. Poster presented at the 32nd CUNY Conference on Human Sentence Processing.

Cummins, Chris \& Hannah Rohde. 2015. Evoking context with contrastive stress: Effects on pragmatic enrichment. Frontiers in Psychology 6. https://doi.org/10.3389/fpsyg.2015.01779.

Djärv, Kajsa \& Hezekiah Akiva Bacovcin. 2017. Prosodic effects on factive presupposition projection. In Dan Burgdorf, Jacob Collard, Sireemas Maspong \& Brynhildur Stefánsdóttir (eds.), Proceedings of Semantics and Linguistic Theory (SALT) XVII. 116-133. Washington, DC: Linguistic Society of America. https://doi.org/10.3765/salt.v27i0.4134.

D'Onofrio, Annette. 2018. Personae and phonetic detail in sociolinguistic signs. Language in Society 47(4). 513-539. https://doi.org/10.1017/S0047404518000581.

Drager, Katie. 2011. Speaker age and vowel perception. Language and Speech 54(1). 99-121. https://doi.org/10.1177/0023830910388017.

Gazdar, Gerald. 1979a. Pragmatics: Implicature, presupposition, and logical form. New York: Academic Press.

Gazdar, Gerald. 1979b. A solution to the projection problem. In Choon-Kyu Oh \& David A. Dinneen (eds.), Syntax and semantics, vol. 11. 57-89. New York: Academic Press.

Geurts, Bart. 1999. Presuppositions and pronouns. Oxford: Elsevier.

Hanulíková, Adriana, Petra M. Van Alphen, Merel M. Van Goch \& Andrea Weber. 2012. When one person's mistake is another's standard usage: The effect of foreign accent on syntactic 
processing. Journal of Cognitive Neuroscience 24(4). 878-887.

https://doi.org/10.1162/jocn_a_00103.

Hay, Jennifer \& Katie Drager. 2010. Stuffed toys and speech perception. Linguistics 48(4). 865892. https://doi.org/10.1515/ling.2010.027.

Heim, Irene. 1983. On the projection problem for presuppositions. In Michael Barlow, Daniel Flickinger \& Michael Wescoat (eds.), Proceedings of the Second West Coast Conference on Formal Linguistics. 114-25. Stanford: CSLI.

Heim, Irene. 1992. Presupposition projection and the semantics of attitude verbs. Journal of Semantics 9(3). 183-221. https://doi.org/10.1093/jos/9.3.183.

Karttunen, Lauri. 1971. Some observations on factivity. Papers in Linguistics 4(1). 55-69. https://doi.org/10.1080/08351817109370248.

Karttunen, Lauri. 1974. Presupposition and linguistic context. Theoretical Linguistics 1(1-3). 181194. https://doi.org/10.1515/thli.1974.1.1-3.181.

Karttunen, Lauri \& Stanley Peters. 1979. Conventional implicature. In Choon-Kyu Oh \& David A. Dinneen (eds.), Presupposition (Syntax and Semantics 11). 1-56. New York: Academic Press.

Kim, Jonny. 2016. Perceptual associations between words and speaker age. Laboratory Phonology 7(1). Article 18. https://doi.org/10.5334/labphon.33.

Kiparsky, Paul \& Carol Kiparsky. 1970. Fact. In Manfred Bierwisch \& K.E. Heidolph (eds.), Progress in linguistics. 143-173. The Hague: Mouton.

Niedzielski, Nancy. 1999. The effect of social information on the perception of sociolinguistic variables. Journal of Language and Social Psychology 18(1). 62-85. https://doi.org/10.1177/0261927X99018001005.

Potts, Christopher. 2005. The logic of conventional implicatures. New York: Oxford University Press.

Roberts, Craige. 1996/2012. Information structure in discourse: Towards an integrated formal theory of pragmatics. Semantics and Pragmatics 5(6). 1- 69. https://doi.org/10.3765/sp.5.6.

van der Sandt, Rob A. 1988. Context and presupposition. London: Croom Helm.

van der Sandt, Rob A. 1992. Presupposition projection as anaphora resolution. Journal of Semantics 9(4). 333-377. https://doi.org/10.1093/jos/9.4.333.

Schlenker, Philippe. 2008. Be articulate: A pragmatic theory of presupposition projection. Theoretical Linguistics 34(3). 157-212. https://doi.org/10.1515/THLI.2008.013.

Seifeldin, Maryam, Max Cantor, Julie Boland \& Jonathan Brennan. 2015. They dropping copulas: Salient cues in the integration of speaker identity and syntax. Poster presented at the 28th CUNY Conference on Human Sentence Processing.

Simons, Mandy. 2001. On the conversational basis of some presuppositions. In Rachel Hastings, Brendan Jackson \& Zsofia Zvolenszky (eds.), Proceedings of Semantics and Linguistic Theory (SALT) XI. 431-448. Washington, DC: Linguistic Society of America. https://doi.org/10.3765/salt.v11i0.3099.

Simons, Mandy. 2005. Presupposition and relevance. In Zoltán Gendler Szabó (ed.), Semantics versus pragmatics. 329-355. New York: Oxford University Press.

Simons, Mandy. 2007. Observations on embedding verbs, evidentiality, and presupposition. Lingua 117(6). 1034-1056. https://doi.org/10.1016/j.lingua.2006.05.006

Simons, Mandy, David Beaver, Craige Roberts \& Judith Tonhauser. 2017. The best question: Explaining the projection behavior of factives. Discourse Processes 54(3). 187-206. 
https://doi.org/10.1080/0163853X.2016.1150660.

Simons, Mandy, Judith Tonhauser, David Beaver \& Craige Roberts. 2010. What projects and why. In Nan Li \& David Lutz (eds.), Proceedings of Semantics and Linguistic Theory (SALT) XXI. 309-327. Washington, DC: Linguistic Society of America. https://doi.org/10.3765/salt.v20i0.2584.

Stalnaker, Robert. 1974. Pragmatic presuppositions. In Milton K Munitz \& Peter K Unger (eds.), Semantics and philosophy. 197-213. New York: NYU Press.

Stevens, Jon, Marie-Catherine de Marneffe, Shari R. Speer \& Judith Tonhauser. 2017. Rational use of prosody predicts projection in manner adverb utterances. Proceedings of the Annual Meeting of the Cognitive Science Society 39. $1144-1149$.

Strand, Elizabeth A. 1999. Uncovering the role of gender stereotypes in speech perception. Journal of Language and Social Psychology 18(1). 86-100. https://doi.org/10.1177/0261927X99018001006.

Tesink, Cathelijne, Karl Petersson, Jos Van Berkum, Danielle Van den Brink, Jan Buite- laar \& Peter Hagoort. 2009. Unification of speaker and meaning in language com- prehension: An fMRI study. Journal of Cognitive Neuroscience 21(11). 2085-2099. https://doi.org/10.1162/jocn.2008.21161.

Tonhauser, Judith. 2016. Prosodic cues to speaker commitment. In Mary Moroney, Carol-Rose Little, Jacob Collard \& Dan Burgdorf (eds.), Proceedings of Semantics and Linguistic Theory (SALT) XXVI. 934-960. Washington, DC: Linguistic Society of America. https://doi.org/10.3765/salt.v26i0.3788.

Tonhauser, Judith, David Beaver \& Judith Degen. 2018. How projective is projective content? Gradience in projectivity and at-issueness. Journal of Semantics 35(3). 495-542.

Tonhauser, Judith \& Judith Degen. 2019. Higher-probability content is more projective than lower-probability content. Paper presented at the 8th Experimental Pragmatics Conference (XPrag).

Van Berkum, Jos JA, Danielle Van den Brink, Cathelijne M. J. Y. Tesink, Miriam Kos \& Peter Hagoort. 2008. The neural integration of speaker and message. Journal of Cognitive Neuroscience 20(4). 580-591. https://doi.org/10.1162/jocn.2008.20054.

Walker, Abby \& Jen Hay. 2011. Congruence between 'word age' and 'voice age' facilitates lexical access. Laboratory Phonology 2(1). 219-237. https://doi.org/10.1515/labphon.2011.007. 